\title{
Amamentação e extensão acadêmica: promovendo a conscientização do direito ao aleitamento materno através do projeto Apoiando a Amamentação na Baixada
} Fluminense

\author{
Breastfeeding and academic extension: promoting awareness of the right to \\ breastfeeding through the Supporting Breastfeeding project in Baixada \\ Fluminense
}

Isabella Henrique Pascoal da Silva ${ }^{1}$ Patrícia Lima Pereira Peres ${ }^{2}$

1 Acadêmica. Universidade do Estado do Rio de Janeiro (UERJ), Brasil. E-mail: isabella.henrique29@gmail.com

2 Professora. Doutora. Universidade do Estado do Rio de Janeiro (UERJ), Brasil. E-mail: patricia.uerj@hotmail.com

Recebido em: 04/02/2019 | Aprovado em: 11/03/2020

DOI: $10.12957 /$ interag.2019.39937

\begin{abstract}
Resumo
O primeiro alimento essencial para o bebê é o leite materno que proporciona nutrientes para um crescimento e desenvolvimento saudável e oferece proteção imunológica para defesa do organismo. 0 incentivo ao aleitamento materno (AM) configura-se entre as políticas públicas de saúde e a que mais tem causado impacto à saúde da criança. Criado em 2007, o Projeto de Extensão "Apoiando a amamentação na Baixada Fluminense, da Faculdade de Enfermagem, da Universidade Do Estado do Rio de Janeiro (UERJ), tem como objetivos: possibilitar ao acadêmico a vivência na implementação e acompanhamento da política de aleitamento materno na Região da Baixada Fluminense, desenvolver competência técnica amparada nas bases científicas em aleitamento materno em graduandos e profissionais de saúde, contribuir para a melhoria das condições de saúde das crianças nessas localidades, capacitar profissionais de saúde para o manejo do aleitamento materno seja em unidade básica, seja em hospital, empoderar mães e pais para favorecer a amamentação e sensibilizar o acadêmico de enfermagem acerca da importância do manejo do AM para a redução da morbimortalidade infantil. O método do projeto consiste nas ações desenvolvidas que visam o fortalecimento da gestão da política de aleitamento nas três frentes: promoção, proteção e apoio. Além disso, o grupo desempenha debates e orientações para as classes populares acerca da conscientização dos seus direitos, da importância e das vantagens da amamentação para o bebê, família e sociedade.
\end{abstract}

Palavras-chave: Amamentação; Direitos Humanos.

\begin{abstract}
The first essential food for the baby is breast milk, it provides nutrients for healthy growth and development and offers immune protection to defend the body. The incentive to breastfeeding is configured between public health policies and the one that most causes the impact on the child's health. Created in 2007, the Extension Project "Supporting breastfeeding in the Baixada Fluminense, Faculty of Nursing, University of the State of Rio de Janeiro (UERJ), aims to: Enable students to experience the implementation and monitoring of breastfeeding policy in the Baixada Fluminense Region, develop technical competence supported by scientific bases on breastfeeding in undergraduates and health professionals, contribute to the improvement of the health conditions of children in these locations, train health professionals to manage breastfeeding in the unit basic, whether in hospital, empower mothers and fathers to favor breastfeeding and sensitize nursing students about the importance of managing breastfeeding to reduce child morbidity and mortality. The project method consists of the actions developed that aim to strengthen the management of the breastfeeding policy on the three fronts: promotion, protection and support. In addition, the group carries out debates and guidelines for the popular classes about the awareness of their rights, the importance and advantages of breastfeeding for the baby, family and society.
\end{abstract}

Keywords: Breast-feeding; Human rights

Área temática: Saúde; Educação.

Linha de extensão: Saúde, Educação. 


\section{Introdução}

A alimentação como um direito humano traz para o centro da discussão a importância dos alimentos e como os países devem se preocupar com este assunto. Dentre o que prevê esse direito está a amamentação, que é o direito da mãe em amamentar o seu filho pelo período de tempo que julgar necessário. Isto torna ainda mais necessária a visibilidade do tema, tendo em vista as diversas condições desiguais em que muitas dessas mães vivem no Brasil e o descaso dos governantes em relação aos direitos dessas mulheres.

Apesar de estar descrito na Constituição Federal (CF) e no Estatuto da Criança e do Adolescente (ECA), ainda existem mulheres e crianças privadas desse direito, sobretudo ao aleitamento materno exclusivo, devido à falta de estrutura nas instituições públicas e privadas que deveriam proteger o livre exercício do aleitamento materno e a saúde da mulher e muitas vezes não o fazem.

No projeto de Extensão "Apoiando a Amamentação na Baixada Fluminense" planejamos ações de promoção, proteção e apoio ao aleitamento materno e, como atuamos na Baixada Fluminense, podemos ter uma experiência prática de como funciona o investimento das Políticas Públicas nos locais e se há questões que interferem na prática do aleitamento materno. Como futuros enfermeiros, realizamos o acolhimento, orientamos quando necessário, estimulamos o vínculo entre mãe e bebê, trabalhamos e incentivamos o aumento de autoestima da mulher e informamos sobre seus direitos como mulher trabalhadora e estudante.

O projeto, através das atividades na extensão universitária, promove uma ligação entre o acadêmico e a sociedade. Dentre as atividades integrativas realizam-se rodas de conversas com gestantes, nutrizes e os acompanhantes para ouvir e sanar as dúvidas que os afligem e que possam dificultar o aleitamento materno. 


\section{Aleitamento materno- avanço histórico}

No Brasil, pelo que se conhece da história, os filhos das indígenas eram alimentados com o leite materno durante um ano. Para que não ficassem sozinhos e com fome enquanto suas mães trabalhavam na floresta para o cultivo e colheita dos alimentos, eles eram levados por elas nas costas ou presos no quadril por um pano conhecido por tpyia. "Do mesmo modo que os animais, as índias nutriam e defendiam seus filhos de todos os perigos. Se soubessem que o bebê tinha mamado em outra mulher, não sossegavam enquanto a criança não colocasse para fora todo o leite estranho”. ${ }^{1}$

Com a chegada da esquadra de Pedro Álvares Cabral, não traziam somente uma cultura a bordo para influenciar a terra tupiniquim, traziam também doenças que acometeram os índios nas tribos, em que muitos deles morreram por não possuírem células de defesa no organismo. Tal fato culminou na criação de instituições para abrigar os índios órfãos, podendo associar a isso como umas das primeiras razões para o desmame precoce. "Os profissionais responsáveis pela assistência também referiam a utilização de práticas "modernas" para alimentar as crianças, como o emprego de mamadeiras de vidro e pequenos bules que tinham um bico de borracha adaptado à ponta de saída”. ${ }^{2}$

Já em 1850, os serviços das amas de leite para o aleitamento materno eram uma boa fonte de renda para o capital dos senhores de escravos, ao anunciar pelo jornal o aluguel dessas mulheres que deveriam ser saudáveis, ter bastante leite e não poderiam ter filhos; caso tivessem deveriam abdicar de amamentá-los para alimentar as crianças dos senhores. "As mulheres brancas nunca amamentam seus filhos e daí os anúncios de escravas para amas de leite, que enchem os jornais da capital”.

Houve um declínio do número de crianças que eram conduzidas até as amas e um progresso do uso das mamadeiras com leite de vaca e, com isso, o prosseguimento das práticas como opções que substituíam o aleitamento materno. Na época atual, os médicos 
começam a prescrever receitas para compra de fórmulas infantis, antes mesmo de os pais saírem da maternidade, acreditando nos benefícios do leite e no caso de a mãe ter dificuldade em amamentar. Com a ascensão das propagandas, as indústrias de leite em pó cresceram, e estimularam a modificação na alimentação do lactente; muitas mães começaram a acreditar que a fórmula vendida pela indústria deixaria seus filhos saudáveis e nutridos. "As soluções dos problemas da alimentação da criança passam a ser vistas pelas mães através do marketing desempenhado pelas indústrias". ${ }^{4}$

No início do século XX, foi adicionada a ideia do "leite fraco" ou "eu não tenho leite". A hipogalactia é um dos fatores mais frequentes de desmame precoce. "Este era um argumento reconhecido cientificamente, que não tornava as mulheres culpadas pelo fracasso na amamentação diante da sociedade e dos profissionais de saúde, sendo assimilado amplamente e utilizado até hoje”. ${ }^{5}$

Em sua composição, o leite materno é classificado em três tipos: o colostro, o leite de transição e o leite maduro. O colostro é um leite rico em proteínas, eletrólitos, vitaminas e anticorpos IgA e sua produção é secretada logo após o parto. O leite de transição é um leite intermediário ao colostro e o maduro, é um leite mais cremoso em cor e textura e sua produção se dá de sete a quatorze dias pós-parto. E o leite maduro é rico em gorduras, proteínas, lactose, fatores de crescimento e vitaminas e minerais.

A amamentação é recomendada pela Organização Mundial de Saúde (OMS) a ser exclusiva até os seis meses de vida, sem a necessidade de introdução de água, chás, sucos, outros leites ou alimentos e, depois dos seis meses, ela deve ser complementada com alimentos saudáveis.” Há casos em que as contraindicações são definitivas como doenças graves ou crônicas, assim como mães infectadas pelo vírus da imunodeficiência humana (HIV), e, ainda, bebês com doenças metabólicas raras como a fenilcetonúria e a galactosemia". 6 
O aleitamento materno (AM) traz vantagens ao bebê como: proteção contra diarreias, infecções respiratórias e alergias; diminui o risco de hipertensão, colesterol alto e diabetes; além de reduzir a chance de desenvolver obesidade". ${ }^{7}$ No aspecto psicológico, a amamentação promove e desenvolve o caráter da criança. As experiências vivenciadas na primeira infância são importantes para determinar a personalidade da criança quando adulto. Segundo Antunes ${ }^{8}$, as crianças que mamam no peito tendem a ser mais tranquilas e fáceis de socializar-se durante a infância.

Também traz benefícios para a mãe como: perda de peso, proteção contra a anemia, câncer de mama, ovário e útero, e funciona como efeito contraceptivo pela amenorreia lactacional (LAM). Este método de planejamento reprodutivo consiste em três processos: a menstruação da mãe ainda não retornou, o bebê tem menos de seis meses de idade e está sendo alimentado em livre demanda somente pelo peito.

Para a família, Giugliani ${ }^{9}$ considera ser de fundamental importância para as famílias mais carentes o fator econômico, visto que o gasto com a compra do leite artificial representa um impacto na renda dessas famílias e, além desse custo deve-se acrescentar aqueles com mamadeiras, bicos e gás de cozinha, além de outros eventuais decorrentes de doenças, que são mais comuns em crianças não amamentadas.

Importante destacar, que a escolha em amamentar, o incentivo e o conhecimento sobre os benefícios do aleitamento materno não garantem a continuação da prática. "Para assegurar sua opção, a mulher precisa estar inserida em um ambiente favorável à amamentação e contar com o apoio de familiares e de profissionais dispostos e habilitados a ajudá-la quando necessário". ${ }^{10}$

\section{O direito de amamentar e de ser amamentado}

A amamentação é uma prática feminina e com ela transita os direitos de primeira geração e os de segunda geração. Os de primeira geração, como o direito à vida, liberdade, 
são direitos garantidos no Brasil, pela Constituição Federal. Os de segunda geração, como os direitos sociais, são resultado das lutas sociais que têm como objetivo a redução da desigualdade social e de gênero no país.

Segundo Quednau ${ }^{11}$, a mulher sempre teve grandes dificuldades para alcançar o seu espaço dentro da sociedade. A ela cabia ser responsável pelos afazeres domésticos, filhos, mas, hoje, isso não é mais assim. Devido às mudanças nas últimas décadas, passaram a identificar uma postura diferente da mulher diante da sociedade.

"Embora a maternidade seja valorizada em nossa sociedade e regida por lei, na prática a possibilidade de engravidar, a gravidez e o cuidado com os filhos são os alvos de discriminações ocorridas contra as mulheres no mercado do trabalho". ${ }^{12}$

A amamentação em condições adequadas é um direito fundamental da criança, como descrito no artigo $9^{\circ}$ do Estatuto da Criança e do Adolescente (ECA), "o Poder Público, as instituições e os empregadores devem propiciar condições adequadas ao aleitamento materno, inclusive aos filhos de mães submetidas à medida privativa de liberdade". ${ }^{13}$

Peres ${ }^{14}$ argumenta que o trabalho é uma questão importante ao se analisar a sua correlação com a amamentação. A participação da mulher no mercado de trabalho vem crescendo a cada dia e hoje há leis que a protegem caso ela queira engravidar e amamentar. $\mathrm{Na}$ fase do aleitamento materno, a mãe tem por direito a sua licença maternidade garantida para ficar afastada do trabalho por no mínimo 120 dias, recebendo o seu salário de forma integral e para o pai o direito a uma licença paternidade de apenas 5 dias. 
Mas nem todas as mães conseguem continuar amamentando os seus filhos de forma exclusiva depois que retornam ao trabalho, pois muitas delas encontram dificuldades por não terem com quem deixar o bebê e sofrem influência da indústria que atua intensamente visando o seu lucro, fazendo com que estas mães acreditem na superioridade da fórmula sobre o leite humano, convencendo-as de que podem substituir o seu leite sem prejuízo algum. Como o leite industrializado é aparentemente prático, a ideia de que qualquer pessoa poderia alimentar o bebê enquanto os pais estivessem trabalhando é um fator que favorece a substituição do alimento. A compreensão das mulheres sobre o aleitamento materno influencia no ato de amamentar e a falta de informação sobre seus direitos pode apresentar consequências, como por exemplo, o desmame precoce.

Já a licença- maternidade para estudante é ainda desconhecida por grande parte da população. A Lei no 6.202, de 17 de abril de 1979, concede à estudante grávida a licença a partir do oitavo mês de gestação e mais três meses após o parto. Para isso, a estudante apresentará na direção da escola/universidade o atestado médico ficando afastada para exercer os cuidados com o bebê. Ela terá exercícios domiciliares como se fossem os exames finais e seu aproveitamento será analisado pelos trabalhos realizados no domicílio. Logo, essa lei assegura a licença- maternidade para as gestantes estudantes, de qualquer idade ou qualquer nível de escolaridade, para que não sejam prejudicadas durante sua formação acadêmica ou que não haja uma evasão escolar devido à carga de responsabilização como mulher. Isto ajuda para que ela tenha desejo de retornar aos estudos e concluir sua formação.

Outro direito que assegura a alimentação da criança é a Norma Brasileira de Comercialização de Alimentos para Lactentes e Crianças de Primeira Infância, Bicos, Chupetas e Mamadeiras (NBCAL), um conjunto de normas que regulamentam a promoção comercial e produtos destinados aos bebês e crianças como mamadeiras, chupetas, leites industrializados, alimentos à base de cereais e papinhas. A norma tem 
como objetivo certificar o uso apropriado desses produtos para que não interfira na amamentação. Alguns produtos só podem ser vendidos com a promoção comercial se estiverem utilizando a frase informativa correspondente ao produto, tendo a intenção de fazer com que a mãe repense na amamentação quando estiver comprando o leite industrializado.

Outra medida para garantir a AM e a promoção da saúde materno-infantil foi a implantação e crescimento da Rede de Bancos de Leite Humano. É uma iniciativa pública vinculada aos hospitais maternidades com UTI neonatal, em que os profissionais são responsáveis por promover e orientar sobre o aleitamento materno, além de exercerem o papel de coleta, controle de qualidade, pasteurização e distribuição dos leites. Toda mulher saudável que produza mais leite do que o suficiente para o seu bebê na amamentação pode se tornar uma doadora e a coleta pode ser feita tanto no próprio banco como na casa da doadora.

As doações dos leites amparam os casos em que a mãe não consegue amamentar ou quando o lactente não pode alimentar-se diretamente no seio por algum motivo. Apesar de termos muitos bancos de leite pelo Brasil, é preciso que haja uma propagação e incentivo para que as mulheres queiram se tornar doadoras. Sabe-se que um litro de leite materno doado pode alimentar até 10 (dez) recém-nascidos por dia.

\section{Projeto Apoiando a Amamentação na Baixada Fluminense}

O projeto "Apoiando a AmamentAÇÃO na Baixada Fluminense" teve início em 2007, tendo como objetivos possibilitar o acadêmico a vivenciar ações de manejo em aleitamento materno na atenção primária e secundária, monitorar a política de aleitamento materno e sua implantação nos municípios. 
Atuamos em uma região populosa com baixo poder aquisitivo e carente dos serviços básicos. Os participantes do projeto desenvolvem suas atividades em parceria com as Secretarias Municipais de Saúde na Baixada Fluminense, proporcionando melhoria na saúde das crianças reduzindo a morbimortalidade, o desmame precoce e a desigualdade social. Além disso, exercemos nos municípios a conscientização dos direitos da mulher e da criança, realizamos a promoção, incentivo e o apoio ao aleitamento materno, porém a inserção precoce de alimentos complementares e pouco nutritivos ainda reflete os hábitos culturais e nutricionais da população.

Dentre as atividades realizadas nos municípios, 7 (sete) membros da equipe durante o mês de julho de 2018, realizaram um monitoramento da NBCAL nas farmácias e mercados da Baixada Fluminense. Com o objetivo de encontrar promoções comerciais desses produtos e verificar se estavam sendo vendidos seguindo os parâmetros da norma e também se havia produtos proibidos para promoção comercial foi utilizado um formulário impresso para observação das práticas de promoção comercial dos estabelecimentos e também foi feita entrevista com o gerente do estabelecimento. Foi considerado que poucos gerentes conheciam sobre as normas da NBCAL. Na finalização da atividade, eles foram orientados sobre os produtos que poderiam ou não ser vendidos com a promoção e sobre suas respectivas fases.

Nas atividades realizadas na universidade, promovemos o "Encontro com Leite", um encontro mensal que ocorreu durante os meses de julho a dezembro de 2018 e que teve como objetivo a discussão de temas relacionados à amamentação e à saúde da criança. Os 10 membros do projeto foram divididos e cada dupla recebeu um tema, como, por exemplo: amamentação cruzada, razões aceitáveis para complementação e substituição do leite humano e direitos e proteção legal da mulher trabalhadora e estudante que amamenta. Baseado em artigos científicos, montamos as apresentações no formato de slides e dissertamos sobre o tema estudado, e, logo após realizávamos uma 
discussão sobre o tema e a relevância dele para nossa formação profissional como enfermeiros.

Além do mais, outra atividade do projeto foi a realização da ação educativa na Clínica da Família Pedro Ernesto no mês de outubro de 2018, em conjunto com a equipe de saúde da mesma, quando realizamos uma oficina com gestantes, mães e acompanhantes sobre os cuidados com a beleza durante este período. Como as mulheres neste período não podem utilizar coloração ou produtos químicos nos cabelos porque estão grávidas ou alimentando os bebês, nós orientamos que elas poderiam utilizar produtos naturais, como a babosa, para fazer hidratação e obter cabelos mais saudáveis e brilhantes, iniciativas como essas contribuem para a elevação da autoestima da mulher.

\section{Considerações Finais}

Como acadêmica de enfermagem e participante do projeto, trabalhamos intensamente na Região da Baixada Fluminense para promover e incentivar o aleitamento materno, orientar e sanar as dúvidas quando for necessário e orientar para que as mulheres saibam dos direitos que as protegem como mulher gestante, trabalhadora e estudante que amamenta. A recomendação é que a criança seja alimentada com leite materno até os dois anos ou mais, sendo exclusivo nos primeiros seis meses, mas nem todas as mulheres conseguem livremente exercer esse direito.

Temos que avaliar e respeitar o ambiente cultural, pois os acompanhantes também influenciam nas decisões que as gestantes irão tomar, principalmente se forem suas mães. Existem áreas em que as mães ou cuidadoras oferecem aos bebês água e chá antes dos seis meses de vida, sob a alegação de que está muito quente, um exemplo de como mitos e costumes podem interferir na prática da amamentação. Como futuros enfermeiros, nosso papel é orientar tanto a mãe como o acompanhante sobre os 
benefícios, importância e como o leite possui todos os nutrientes necessários, inclusive água para a sede do bebê.

O nosso planejamento para atuar como extensão universitária tem sido dificultado por diversas barreiras. A UERJ passa por tempos difíceis, com um desmonte nas universidades públicas. Isto ocorre devido à falta de repasses do governo e, como consequência, a precarização da estrutura da universidade, os atrasos dos salários dos professores e das bolsas de permanência dos alunos que dificultam sua ida até a universidade para exercer as suas atividades. A educação pública de qualidade está sendo asfixiada para dar lugar a ideia de que uma universidade particular não passa pelos mesmos problemas e que o estudante terá prazo para começar e para se formar, o que não é garantido na universidade pública devido às greves.

A importância da pesquisa extensionista vai além da faculdade. A sociedade brasileira se desenvolve, também, com os projetos acadêmicos que tornam mais relevantes as questões sociais, fazendo com que os direitos dos cidadãos sejam garantidos.

O sistema educacional brasileiro depende de pessoas comprometidas com a pesquisa extensionista, a fim de salientar em sala de aula a relevância dos dados obtidos através dos projetos acadêmicos. Com a extensão, os alunos se tornam críticos, realizam pesquisas científicas segundo os resultados das investigações, atuam junto da sociedade para resolução dos problemas e reduzir a desigualdade social.

\section{Contribuição dos autores}

O texto foi elaborado através de pesquisas em artigos científicos, utilizando buscas em bases de dados e através do Google acadêmico e da vivência como acadêmica de enfermagem e bolsista do projeto de extensão "Apoiando a Amamentação na Baixada”. O projeto nos auxilia a aprimorar o conhecimento além das disciplinas dadas em sala de 
aula. Ser moradora da Baixada Fluminense é reconhecer os problemas sociais que existem em nossos municípios e junto com a faculdade iremos planejar e implementar ações para incentivar o aleitamento materno e reduzir o desmame precoce, promover o autocuidado para que as mães consigam cuidar de seus filhos e orientar sobre os direitos sociais que as protegem.

\section{Referências bibliográficas}

1. Raminelli R. Eva Tupinambá. In: Priore MD, Bassanezi C. História das mulheres no Brasil. 2.ed. São Paulo: Contexto; 1997.

2. Priore MD. História das mulheres no Brasil. 2ed. São Paulo: Contexto; 1997

3. Schlichthorst, Carl. O Rio de Janeiro como é (1824 - 1826): uma vez e nunca mais: contribuições de um diário para a história atual, os costumes e especialmente a situação da tropa estrangeira na capital do Brasil. Tradução de Emmy Dodt e Gustavo Barroso. Brasília: Senado Federal, 2000. (Coleção O Brasil visto por estrangeiros).

4. Nakano AMS. O aleitamento materno no cotidiano. [tese]. Ribeirão Preto (SP): Doutorado de Enfermagem em Saúde Pública, Escola de Enfermagem USP; 1996

5. Almeida JAG. Amamentação: um híbrido natureza - cultura. Rio de Janeiro: Fiocruz; 1999. 166p.

6. Levy, L.; Bértolo, H. Manual de Aleitamento Materno. UNICEF, Lisboa, p. 5-41, 2008. Disponível em: http://www.unicef.pt/docs/manual_aleitamento.pdf Acesso em 20 dezembro de 2010.

7. BRASIL. Ministério da Saúde. Secretaria de Atenção à Saúde. Departamento de Atenção Básica. Saúde da Criança: Nutrição Infantil, aleitamento materno e alimentação complementar. Caderno de Atenção Básica n. 23. Brasília - DF, 2009.

8. Antunes, L. S. et al. Amamentação natural como fonte de prevenção em saúde. Ciência \& Saúde Coletiva: 103-109, 2008.

9. Giugliani ERJ. O aleitamento materno na prática clínica. J Pediatr 2000; 76(Supl.3):S238-S252.

10.Giugliani ERJ, Lamounier JA. Aleitamento materno: uma contribuição científica para a prática do profissional de saúde. J. Pediatr. 2004; 80(Supl. 5): S117-S118. 
11. Quednau, F. S. O conflito entre a maternidade e o trabalho na mulher PósModerna. Trabalho de conclusão de curso. Monografia apresentada ao Centro Universitário de Brasília. Faculdade de Ciências da Saúde - FACS CURSO: PSICOLOGIA. 2007.

12. Pavesi O. Maternidade - Principal Fator de Discriminação Contra a Mulher. Estudo do Psicólogo, Epecialista em Psicodrama e Psicologia Hospitalar. Santa CatarinaC.2004.

13. BRASIL. Ministério da Saúde. Secretaria de Atenção à Saúde. Departamento de Atenção Básica. Saúde da Criança: Nutrição Infantil, aleitamento materno e alimentação complementar. Caderno de Atenção Básica n. 23. Brasília - DF, 2009.

14. Peres, P. L. P. Amamentação como valor humano, prática feminina e direito social: Contribuição crítica à política pública sustentada no referencial de justiça de Amartya Sem. Tese (doutorado em enfermagem) - Faculdade de Enfermagem, Centro Biomédico, Instituto de Medicina Social, Universidade do Estado do Rio de Janeiro. Rio de Janeiro, p. 43-45. 